\title{
Tests of the vehicle's power unit with fuel cells at a reduced ambient temperature
}

The article presents the results of preliminary tests of the vehicle's powertrain with fuel cells, carried out in a thermoclimatic chamber in a reduced temperature box. The aim of this research is to facilitate the introduction of this type of vehicle to the market and guarantee correct operation in changing climatic conditions. In tests, the use of a new type of vehicle drive system and the use of hydrogen as a commonly available fuel is of great importance.

Key words: fuel cell, hydrogen, thermoclimatic chamber, low temperature

\section{Introduction}

The search for new sources of propulsion, which in the near future may replace piston combustion engines is currently a priority in the work of research teams dealing with automotive vehicles. New propulsion sources must meet a number of requirements related to the expectations of customers accustomed to classic propulsion systems, in addition, they must be simple and cheap to operate, and must not pollute the environment. Vehicles with electric drive, in which electric energy is stored in batteries, do not meet the aforementioned conditions, although they are currently very preferred. At the current stage of development they can only serve as urban vehicles, but they are not suitable for intercity traffic as well as for the drive of heavy commercial vehicles or construction machines. The transitional phase is vehicles with hybrid propulsion systems that only partially meet today's requirements. In this situation, only the propulsion system, equipped with hydrogenpowered fuel cells, can compete with classic reciprocating diesel engines. Currently, only few manufacturers offer vehicles with this type of propulsion system. Their widespread introduction to the market requires proper preparation, the important step of which will be comprehensive research conducted in various operating conditions. One of the most difficult conditions for using a fuel cell drive unit is the winter period, when the ambient temperature decreases below $0^{\circ} \mathrm{C}$. This is due to the fact that during operation the water is released as a result of combining hydrogen with oxygen, therefore the operation of hydrogen fueled fuel cells at low ambient temperatures requires special procedures.

European Union countries belong to the group of countries where vehicles equipped with a new type of propulsion source will first appear on the market. Therefore, preparatory measures should be taken now to facilitate their market introduction and guaranteeing proper operation. What matters here is not only the use of a new type of propulsion system, but also the use of hydrogen as a commonly available fuel. An important factor that should be considered here are climate conditions. In a large part of Europe there is a temperate climate, which is characterized by high variability of temperature and humidity in particular seasons. In the case of operation in this area of vehicles equipped with hydrogen fuel cell drive, it is very important that the vehicle behaves in winter, when the temperature reaches a mini- mum value of around $-20^{\circ} \mathrm{C}$, and there are large temperature fluctuations in the 24-hour cycle. In low ambient temperature, the working conditions of many structural elements of the vehicle's propulsion system are changed, relatrelated to the phenomenon of thermal expansion, and also to the phenomenon of condensation and changes in density of gaseous factors, as well as freezing of liquid agents. The mentioned phenomena are particularly important in the propulsion system of a vehicle equipped with fuel cells, where the fuel used is hydrogen, which requires appropriate conditions to maintain the tightness of the power supply system. In addition, the water drainage system resulting from the reaction of hydrogen with oxygen in the fuel cell requires special thermal conditions and purification procedures.

In connection with the above, before the introduction of this type of vehicles to the market, relevant from the point of view of operational safety, will be research conducted in various climatic conditions, especially at low ambient temperature.

\section{The scope of tests of a vehicle powered by fuel cells}

At the Cracow University of Technology a preliminary vehicle was equipped with hydrogen-powered fuel cell drive. The object of the research was a Toyota Mirai car in a standard version, equipped with an electric drive system and fuel cells, supplied with hydrogen with a purity of 99.97\% $\mathrm{H}_{2}$ stored under 700 bar pressure in two tanks made of composite materials. These tests were carried out in an accredited thermoclimatic chamber that allows a quick change in the ambient temperature. The chamber with dimensions: $23.7 \times 6.9 \times 6.5 \mathrm{~m}$, belonging to the Termoclimatic Research Laboratory of the Cracow University of Technology, allows testing of various types of facilities, including vehicles, in the temperature range from -50 to $+70^{\circ} \mathrm{C}$.

The main goal of the research was to gain operational experience, allowing for better market preparation for the widespread introduction of this type of vehicles into operation. The scope of the research has been limited to a preliminary analysis of the operation of individual construction units of the power unit at a reduced temperature, in particular the hydrogen supply system for fuel cells. An important goal here was to pay attention to the tightness of the entire hydrogen supply system to the fuel cell during the change 
of operating temperature. The second important goal was to assess the thermal insulation of the key components of the propulsion system, including in particular the fuel cell, hydrogen tanks and steam evacuation system. carried out by analyzing the change in temperature.

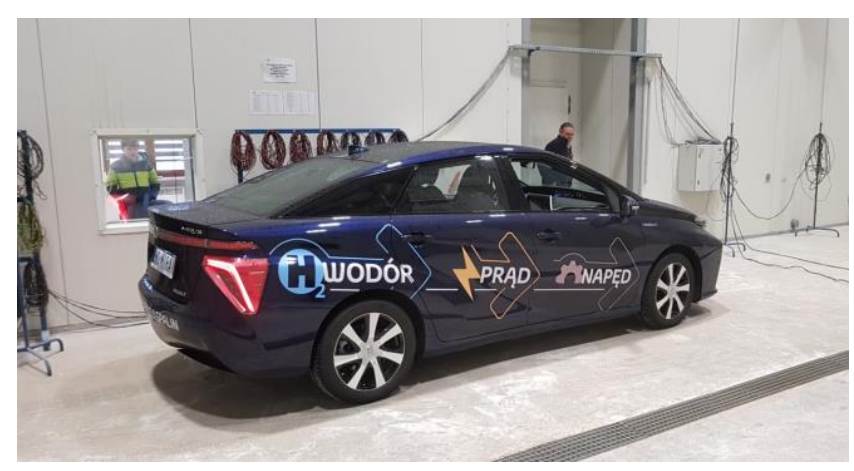

Fig. 1. Toyota Mirai during tests in the thermoclimatic chamber

\section{Procedures used when operating fuel cells at low ambient temperature}

During the operation of a fuel cell vehicle, manufacturers foresee the use of special procedures to protect the fuel cell, the power supply system and the antifreeze outlet system. When operating a Toyota Mirai at an ambient temperature below $-10^{\circ} \mathrm{C}$, certain activities are provided to protect the cells and other systems against damage. The diagram of these activities in various operating states of the drive system is shown in Fig. 2.

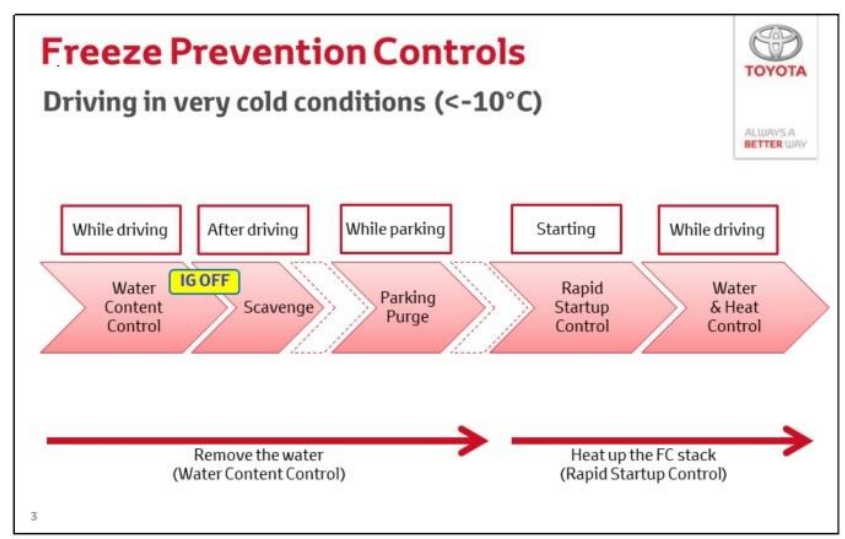

Fig. 2. Diagram of procedures for protecting the fuel cell of the Toyota Mirai at reduced ambient temperature [6]

The most important purpose of these special procedures is to remove water and dry the fuel cell components.

No matter what the ambient temperature is, the fuel cell stack temperature is monitored every hour. If the fuel stack temperature gets below $0^{\circ} \mathrm{C}$, a parking purge is performed and the air compressor, hydrogen pump and discharge valve are activated for up to 3 minutes in order to purge the water from mainly the anode side. In this case water builds up in the anode after switching off ignition due to condensation. When operating a fuel cell at a reduced ambient temperature, the excess water accumulating in the fuel cell and outlet system must be constantly removed. If the ambient temperature is below $-10^{\circ} \mathrm{C}$ special cold spec purge will take place. This special cold purge is different than the normal purge in the way that the water purge is controlled in a much very precise way.

The cold purge will take around 40 seconds and will dry the cathode effectively. But, even with a dry stack, at $-30^{\circ} \mathrm{C}$, it is possible that the very first water drops will immediately freeze. Therefore we need the so-called Rapid Startup Control that makes sure that this does not happen.

When the electronic control unit of fuel cell determines the system temperature is $0^{\circ} \mathrm{C}$ or lower or ambient air temperature is $-10^{\circ} \mathrm{C}$ or lower while the vehicle is left alone, the air amount supplied to the fuel cells is restricted and the a large amount of heat is generated by the fuel cell stack assembly to warm up the system and prevent water from freezing. During the quick warm up, the fuel cell current amount is larger than normal even at the same output as power generation is prioritized during driving. As a result, the fuel cell air compressor and hydrogen pump operate at a higher speed than normal causing a noise to be produced.

In relation to the operation of standard piston combustion engines, the described activities related to fuel cell operation are completely different. Therefore, research to prepare users for the operation of new powertrains is warranted.

\section{Research methodology}

Research on the Toyota Mirai was conducted in a thermoclimatic chamber in the temperature range from $-10^{\circ} \mathrm{C}$ to $-18^{\circ} \mathrm{C}$, which corresponds to the average temperature occurring in winter in the temperate climate zone. The vehicle was inserted into the chamber with an unheated link, and the test time was about 2.5 hours.

Measurements of many different physical quantities characterizing the operation of the drive unit were carried out, using signals available in the vehicle's on-board diagnostic system, read from the factory diagnostic system of Toyota. Particular attention has been paid to those parameters that have an impact on the operational safety of the drive system at a reduced temperature. The following parameters were measured:

- Measurement time,

- Temperature in the thermoclimatic chamber,

- Hydrogen pump motor temperature,

- Smoothed value of hydrogen tank 1 temperature,

- Smoothed value of hydrogen tank 2 temperature,

- FC stack coolant temperature (FC Stack Outlet),

- Smoothed value of fc stack coolant temperature (Radiator Outlet),

- FC stack coolant temperature (Radiator Outlet),

- Smoothed value of intake air temperature,

- Smoothed value of fc stack air temperature (FC Stack Inlet),

- Hydrogen pressure in high, medium and low pressure circuits.

\section{Investigation results}

During the measurements lasting about 2.5 hours, every hour the procedure of checking the condition of fuel cells was switched on, and in addition it was necessary to perform maintenance activities related to the need to enter service inside the chamber. This is manifested by temporary 
changes in the temperature in the chamber. Therefore, the graph additionally includes a trend line, which indicates a continuous decrease in the temperature in the chamber, which during the tests varied from approx. $-11^{\circ} \mathrm{C}$ to approx. $-18^{\circ} \mathrm{C}$.

The most sensitive element of the propulsion system is the Toyota Mirai car for lower temperatures are the individual segments of the fuel cell stack. During the tests in the thermoclimatic chamber conducted in the temperature range from $-11^{\circ} \mathrm{C}$ to $-18{ }^{\circ} \mathrm{C}$ in about 2.5 hours, the temperature of the fuel cell liquid cooler cooled very slowly and during the tests was above $0^{\circ} \mathrm{C}$, and its sudden increase took place with the activation of the cells (Fig. 3). A similar change was shown in the air temperature surrounding the stack of cells, where its value was significantly lower, which resulted from the existing air exchange between the interior of the vehicle and the thermoclimatic chamber (Fig. 3).

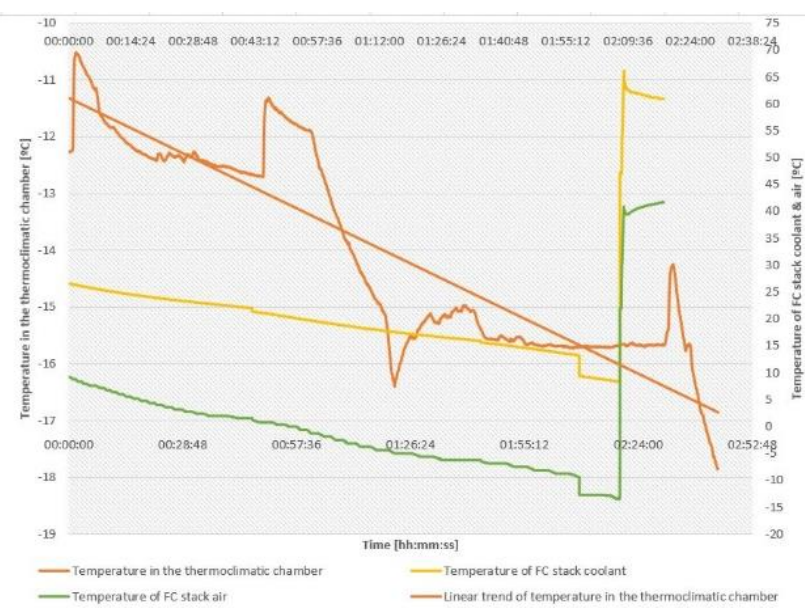

Fig. 3. The temperature of the cooling medium of the fuel cell stack and the air in the cell segments, during the tests of the vehicle in the thermoclimatic chamber

An important parameter describing the working conditions of the fuel cell is the temperature course in the fuel cell intake system (Fig. 4). The changes in the temperature values recorded on the chart are related to the flow of air

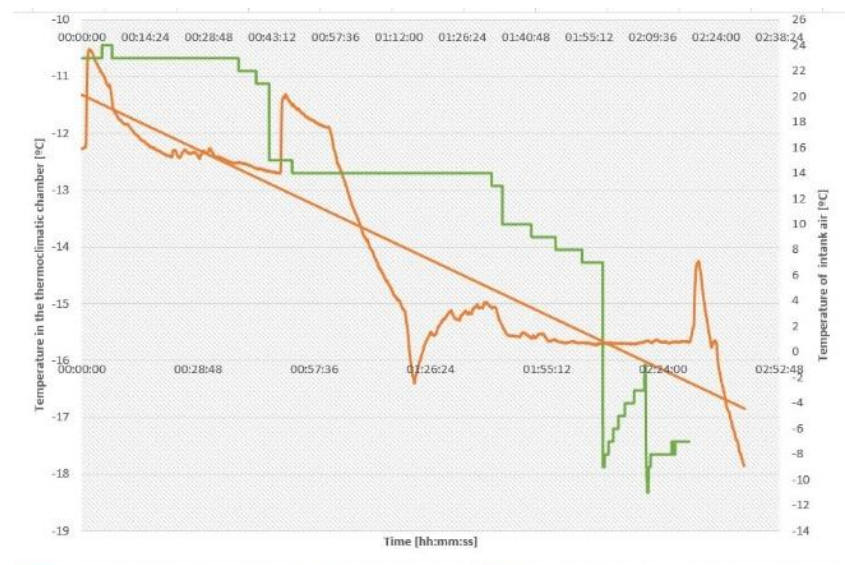

Fig. 4. Air temperature in the fuel cell intake system during vehicle tests in the thermoclimatic chamber supplied to the fuel cell, both during its operation and during the rinsing procedure. The size of this change depends on the value of the air flow which travels from the thermoclimatic chamber to the inside of the cell.

When the vehicle is stationary at a temperature below $0^{\circ} \mathrm{C}$, the procedure for cleaning the surface of the cells from the water is activated. This is manifested by the periodic switching on of the air compressor and the hydrogen pump in order to dry the surface. In Fig. 5. The temperature change of the engine driving the hydrogen pump is presented along with the temperature decrease in the thermoclimatic chamber. Visible, abrupt temperature changes are associated with the pump switching on, because its operation causes the gases to move and the cooling of its components. The sudden increase in temperature of the hydrogen pump seen in Fig. 4 occurred after switching on the fuel cell.

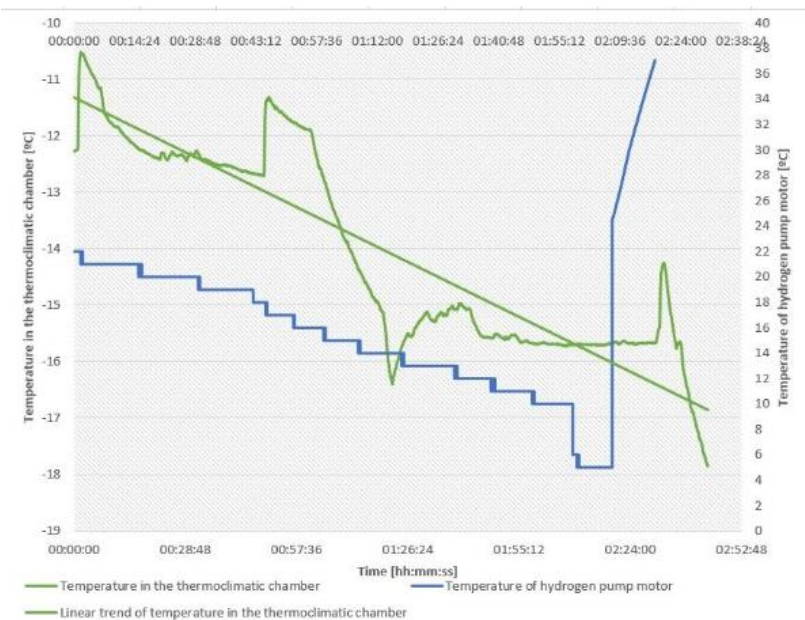

Fig. 5. Temperature of the hydrogen pump during testing of the vehicle in the thermoclimatic chamber

Figure 6 shows the temperature change of hydrogen tanks along with the temperature change in the thermoclimatic chamber. The sudden increase in temperature in the final part of the chart was related to the activation of fuel cells. The temperature of the hydrogen tanks changes much

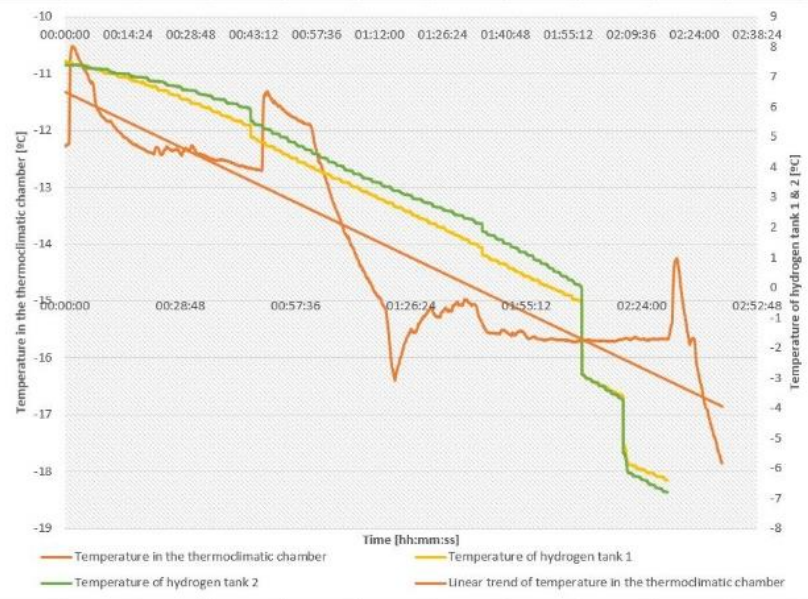

Fig. 6. Temperature of hydrogen tanks during vehicle tests in a thermoclimatic chamber 
more slowly than the temperature of the air in the thermoclimatic chamber, while a significant reduction in their temperature occurs with the start of the fuel cell and the outflow of hydrogen. This is inter alia related to the air movement around the hydrogen tanks.

During measurements in the thermoclimatic chamber, the pressure was also measured in individual circuits of the power system (Fig. 7). The high pressure circuit has included part of the power supply directly after the hydrogen tanks, the medium pressure circuit is responsible for supplying hydrogen to the fuel cells, while the low pressure circuit is already in the fuel cell itself. Despite the change in ambient temperature, the pressure in particular circuits had a stable value. The only significant change in pressure occurs when the cell is started when the hydrogen flowing out of the tanks undergoes heating processes.

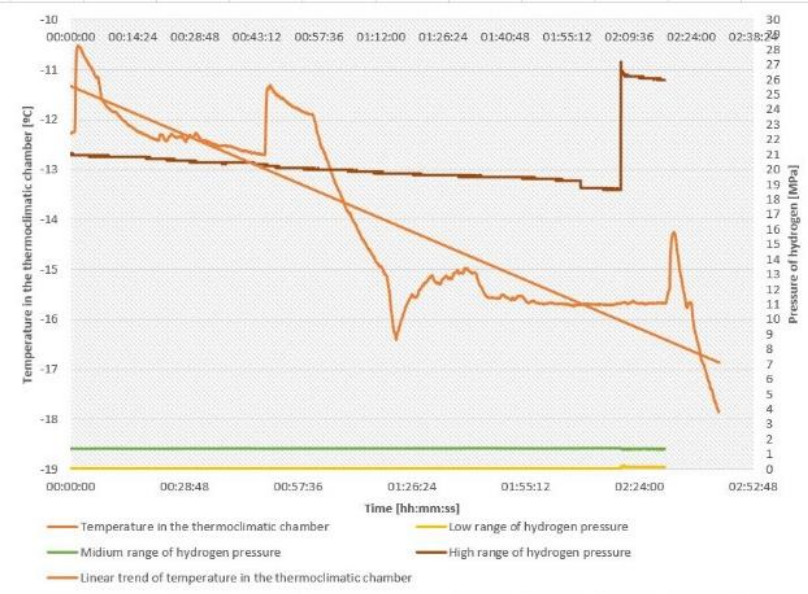

Fig. 7. Hydrogen pressure in high, medium and low pressure circuits during vehicle tests in a thermoclimatic chamber

After the tests, all external parts of the vehicle were covered with ice, while the drive unit and installations were covered with moisture (Fig.8). Despite this, there were no problems with the starting of the vehicle's propulsion system and the operation of all components.

During and after the tests, attention was paid to phenomena that may be significant from the point of view of the operation of the vehicle with the drive system equipped with fuel cells. After completing the tests in the thermoclimatic chamber, all internal components of the vehicle were covered with water molecules. Due to the protection procedures of the fuel cell against the effects of low temperature, many electric circuits of the drive system maintain voltage, and the phenomenon of water condensation on these elements can lead to uncontrolled current flows. In this connection, attention was paid to the phenomenon of condensation of water vapor on individual vehicle systems, and especially on all types of electrical connections and the system of hydrogen supply from pressure cylinders to the fuel cell. In addition, a reduced temperature can affect the tightness of the hydrogen fuel supply system. There were no cases of freezing of moisture particles covering the outlet system, which may lead to the loss of the system's patency.

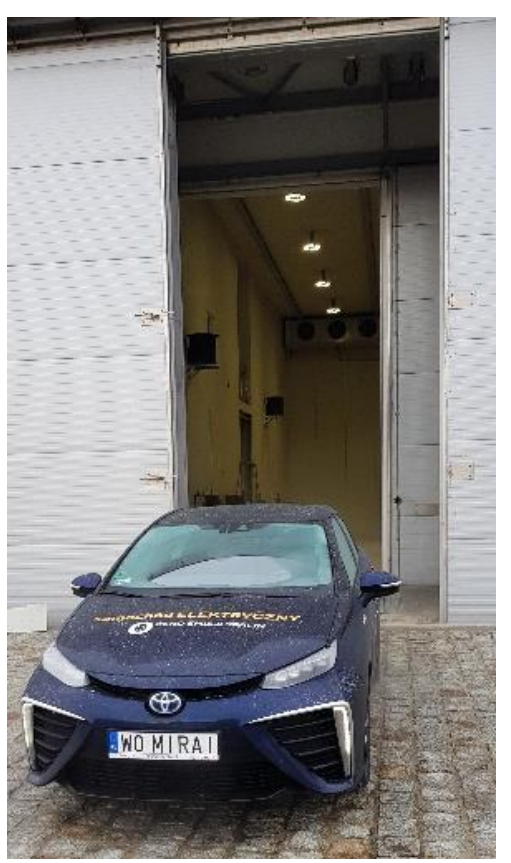

Fig. 8. Toyota Mirai after testing in a thermoclimatic chamber

A very important effect of the research in the thermoclimatic chamber was the opportunity to learn the course of procedures used in vehicles with FC drive system at a reduced ambient temperature.

\section{Conclusions}

- The operating principle and operating procedures of the vehicle's power unit with fuel cells are completely different to those known from power units with combustion engines,

- Preliminary operational tests are very important to help implement a new type of drive system for common use,

- Climatic conditions are a very important factor affecting the operation of fuel cells, therefore the tests carried out in the thermoclimatic chamber are fully justified and necessary,

- Because the factor released from the fuel cell into the atmosphere is water, it is particularly important to collect experience in the operation of this type of vehicle source at a reduced temperature,

- The tests have initial character and are used to identify phenomena and problems occurring during the operation of the power unit equipped with a fuel cell fueled with hydrogen,

- The operation of the vehicle's power unit, equipped with hydrogen fuel cells, in conditions of low temperature requires special procedures that are not used in other vehicle driving units,

- Particular attention has been paid to the operation of elements of the hydrogen supply system in conditions of low temperature,

- During the tests, it was found that many components of the drive system, including the live electrical connections and systems, were covered with a layer of condensed water during the tests. At the same time, no disturbances in their operation were found. 


\section{Bibliography}

[1] BRZEŻAŃSKI, M., CISEK, J., MAREK, W., PAPUGA, T. Investigation of the combustion engine fuelled with hydrogen. V Congress on Combustion Engines. PTNSS- 2013-SC192, Bielsko Biała 2013.

[2] BRZEŻAŃSKI, M., CISEK, J., MAREK, W. et al. Investigation of the combustion engine fueled with hydrogen and mixed n-butanol with iso-butanol. V Congress on Combustion Engines. PTNSS- 2013-SC-194, Bielsko Biała 2013.

[3] BRZEŻAŃSKI, M., MARECZEK, M., MAREK, W., PAPUGA, T. Determination of operating parameters of industrial engine fuelled with post processing gases with high hydrogen content. IOP Conference Series: Scientific

Marek Brzezanski, DSc., DEng. - Faculty of Mechanical Engineering, Cracow University of Technology.

e-mail: mbrzez@pk.edu.pl
Conference on Automotive Vehicles and Combustion Engines. 2016.

[4] BRZEŻAŃSKI, M., PAPUGA, T., RODAK, Ł. Analysis of creation and combustion process of hydrogen-air mixtures by optical method in isochoric chamber. Combustion Engines. 2017, 170(3).

[5] Instruction manual for the thermoclimatic chamber. Cracow University of Technology. Termoclimatic Research Laboratory, Cracow 2018.

[6] Toyota Mirai - Freezing prevention. Toyota Owner's Manual 2018.

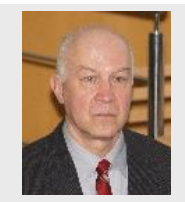

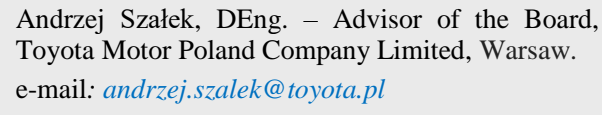

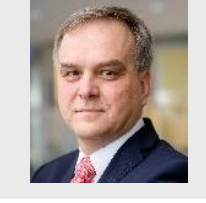

Mateusz Szramowiat, MEng. - Faculty of Mechanical Engineering, Cracow University of Technology. e-mail: mateusz.szramowiat@pk.edu.pl 